\title{
Socio-Technical considerations for Spectrum Access System (SAS) design
}

\author{
Martin BH Weiss \\ (Corresponding Author) \\ School of Info. Sciences \\ University of Pittsburgh \\ Pittsburgh, PA \\ Email: mbw@pitt.edu
}

\author{
William H Lehr \\ CSAIL \\ MIT \\ Cambridge MA \\ Email: wlehr@mit.edu
}

\author{
Amelia Acker \\ School of Info. Sciences \\ University of Pittsburgh \\ Pittsburgh, PA \\ Email: aacker@pitt.edu
}

\author{
Marcela M. Gomez \\ School of Info. Sciences \\ University of Pittsburgh \\ Pittsburgh, PA \\ Email: mmg62@pitt.edu
}

\begin{abstract}
Spectrum Access Systems (SAS) are emerging as a principal mechanism for managing the sharing of radio spectrum. The design of the SAS depends on the specification of spectrum property rights and the governance system by which those rights are enforced. Current perspectives on SAS design have been too limited, focusing narrowly on the technical components without adequate consideration of socio-technical factors that will impact the likely success of any SAS design.

In this paper, we apply the social science literature on the management of common pool resources (CPR) to the design challenge for the SAS. Heretofore, too much of the discussion has focused on an overly simplistic characterization of the spectrum rights design space as a dichotomous choice between licensed $v$. unlicensed, markets v. government, and exclusive v. open. The CPR framework forces consideration of a wider class of design options, positioning the specifications of spectrum property rights more appropriately along a multi-dimensional continuum of rights bundles. The CPR framework highlights the importance of considering formal and informal, multi-layered institutional and market-based interactions among SAS stakeholders when designing a resource management system. We will explain how this leads one to view the SAS as a polycentric governance system (using the terminology in the CPR literature). By examining the economic and social context of spectrum sharing, we assert that these emerging systems must be sufficiently flexible to adapt to various forms of resource governance, which refers to the process by which rights are distributed among stakeholders, how those rights are enforced, and how the resource is managed. We illustrate how the insights from the CPR literature might be implemented in a prototype SAS architecture.
\end{abstract}

\section{INTRODUCTION}

The PCAST report [1] concluded that the future of spectrum management should be increased reliance on shared spectrum. That means sharing in multiple ways and under diverse regimes that will include licensed, unlicensed and other new sharing models. A key component of the PCAST vision is the development of a Federal Spectrum Access System (SAS) to serve as an "information and control clearinghouse for the band-by-band registrations and conditions for use" to "enable flexible sharing of spectrum" in "collaboration with industry partners." Appropriately designed, the SAS will be a key component of the spectrum management regime, helping to match spectrum users with access rights (market-making) and ensure appropriate interference protection (enforcement).
Indeed, at a meta level, the SAS may be viewed as the evolutionary trajectory of spectrum management from the legacy framework of static spectrum assignments toward a dynamic, informative, and flexible management system that allows spectrum resources to be shared on a much more granular basis with respect to electrospace ${ }^{1}$. The frequency allocation chart ${ }^{2}$ is commonly used to explain the challenges of spectrum management reform by illustrating the confusion of overlapping and fragmented block assignments to heterogeneous users and uses. This map and the spectrum management regime it visually summarizes is static, uninformative, and inflexible. It is hard to modify when technology, business, or regulatory changes indicate that spectrum rights should be shifted to new, higher-value uses. It is uninformative and opaque in so far as the rights assignments are difficult to discern and clarify even for active industry stakeholders. These assignments are a hodgepodge of legacy and inconsistent rules that lack clear documentation, making it difficult to reconcile conflicting rights claims and thereby complicating all aspects of spectrum management.

At the core of current proposals for the SAS is a database system that has benefited significantly in terms of its design from the advances made in developing a TV White Space (TVWS) framework for sharing broadcast spectrum. ${ }^{3}$

To date, much of the effort on SAS design has focused overly narrowly on the technical aspects of the system. This is akin to designing an $\mathrm{AI}$ expert system without considering the user and the environment in which the expert system will be used as part of the system being designed. As we move toward the implementation of these systems, we believe that it is important to consider the range of social and institutional approaches that may emerge to govern particular spectrum sharing situations and ensure that SAS designs do not preclude likely spectrum governance arrangements.

\footnotetext{
${ }^{1}$ DeVany [2] and Matheson [3], [4] have attempted to codify the technical aspects of spectrum and have coined the term 'electrospace' to capture the complex aspects of spectrum. In its simplest form, electrospace consists of a 3-tuple of time, frequency and physical space.

${ }^{2}$ See http://www.ntia.doc.gov/files/ntia/publications/2003-allochrt.pdf

${ }^{3}$ Weiss et al. [5] discuss the cost and other benefits of using database driven systems in many kinds of spectrum sharing situations.
} 
We begin by putting SASs into a theoretical perspective. If SAS-based spectrum sharing systems achieve even a small level of success, they promise to be an "infrastructure" as defined by Bowker et al. [6] as a "pervasive enabling resource". As such they are a technical embodiment of a particular set of social agreements.

Thus, we may benefit from the science and technology studies literature. Bowker et.al. [6] observe that “ ... in building cyberinfrastructure, the key question is not whether a problem is a 'social' problem or a 'technical' one. That is putting it the wrong way around. The question is whether we choose, for any given problem, a primarily social or a technical solution, or some combination." More broadly, we can approach SAS design as a "configuration" [7] that joins both technological and social considerations (i.e., "socio-technical"). Further, there has been a relatively recent turn toward studies of large scale infrastructures in society that may inform the design of SASs [8], [9]. Indeed, the mechanisms for sharing radio spectrum constitute a large technological system (LTS) that is defined by its complexity, legacy, stakeholders, and its current and future impact on society [10]. This literature makes clear that the heterogeneous nature of infrastructures, including their embeddedness in practice means that they cannot be separated from how people use, act with, and enable them.

The contribution of this paper is to ground spectrum sharing in general and SASs in particular in the socio-economic literature. This will provide the foundation for sound policy development and analysis going forward, enabling a systematic framework for reasoning about stakeholders, their rights, the enforcement of those rights, and the technologies that enable the resulting policies.

\section{Spectrum as a Common Pool Resource}

Much of the debate over the economic and legal aspects of spectrum management has focused on how the bundles of property rights over spectrum should be defined, allocated, and managed (which includes enforcement of interference protection) so as to best maximize the social and economic benefits from sharing our spectrum resources. ${ }^{5}$ The literature on the management of Common Pool Resources (CPR) provides a useful framework for examining alternative options for the design of spectrum rights bundles and their management that explicitly forces joint consideration of the socio-technical

\footnotetext{
${ }^{4}$ Bowker et al. [6] define infrastructure to include all of the technology and tangible elements (i.e., the machines, bricks \& mortar, roads, etc.) as well as the standards, business processes and other intangibles that together help define how infrastructure is used and evolves. Viewed in this way, infrastructure (like spectrum) may be viewed as a public resource that needs to be managed so that it evolves to meet society's needs.

${ }^{5}$ The early debate often characterized legacy spectrum management as "Command \& Control," (C\&C) which referred to centralized government management of all aspects of spectrum usage. C\&C evoked images of the inefficiencies of Soviet-era central planning and was contrasted with more efficient market-based approaches. The debate often focused on the relative advantages of licensed v. unlicensed regimes, where licensed was equated with private property and unlicensed with a "commons." In truth, both of these regimes are property rights regimes, just with rights defined and managed differently.
}

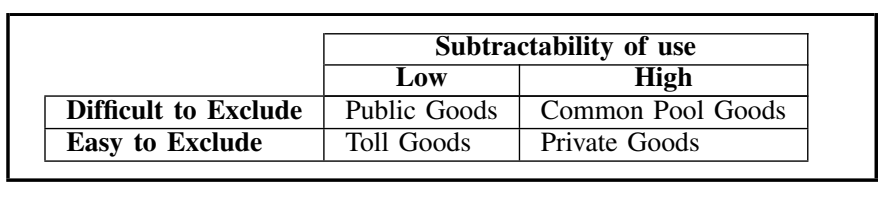

TABLE I

TYPES OF ECONOMIC GOODS

factors that impact how the resource should be governed in specific contexts. ${ }^{6}$

Ostrom [11], a leading CPR scholar, argued that there are four broad categories of economic goods that can be differentiated as shown in Table I. Briefly, subtractability of use is a term intended to capture whether one person's use of a good diminishes someone else's ability to use the same good. For example, most tangible goods (e.g. food) have high subtractability of use since at most one person can consume it. Public goods (e.g., national defense) have low subtractability of use, since we all "consume" it without diminishing someone else's ability to consume it. Subtractability of use relates to the extent to which a resource may be shared. Lower subtractability of use implies expanded options for sharing.

As to the other dimension, much discussion of the economic literature focuses on the ease of excluding people from the consumption of a good. It is generally thought that excluding someone from consuming national defense is difficult, since when it is provided for anyone, it is provided for everyone. Conversely, it is relatively easy to exclude people from the consumption of tangible goods through the use of physical barriers (e.g., locks, doors). ${ }^{7}$ Excludability, which is associated with private goods, makes it feasible to decentralize resource management through competitive markets. ${ }^{8}$

Table I juxtaposes these two dimensions to produce four types of economic goods. The earlier model divided goods into two types: private (e.g., food, tangible goods) and public (e.g., national defense). ${ }^{9}$ Ostrom's refinement added two new categories: Toll goods and Common Pool goods. Toll goods are represented by examples such as movie theaters and limited access highways, where exclusion is relatively easy but subtractability of use is low. ${ }^{10}$ Finally, common pool goods -

\footnotetext{
${ }^{6}$ Ostrom and other CPR scholars recognize that real resources are neither strictly private nor public goods, but exist along a continuum, and that real management regimes are more nuanced and not simply $\mathrm{C} \& \mathrm{C}$, private property, or open access commons.

${ }^{7}$ Ease of exclusion is clearly influenced by technology. The centuries old "arms race" between thieves and locksmiths is but one example of this.

${ }^{8}$ Excludability enables resource owners to contract with consumers/users, thereby enabling the resource to be priced and traded via markets. This forces the resource owner to internalize the implications of decisions for the value of the resource, and competition provides strong incentives to use the resource efficiently. Demsetz [12] describes how resources evolve from common to private goods as markets evolve.

${ }^{9}$ Samuelson's 1954 [13] classification of goods divided the world into two types: private and public, which were rival/excludable and non-rival/nonexcludable in consumption. Ostrom's refinement into four categories recognizes that subtractability (or rivalness) and excludability are not binary but a question of degrees (varying from low to high, easy to difficult).

${ }^{10}$ Buchanan [14] characterized these as "club goods," or goods which are collectively owned and managed, like a golf club.
} 
or, equivalently, common pool resources (CPRs) - are often exemplified by natural resource systems (such as fisheries), where exclusion is costly and subtractability (or congestion) of use is present.

The economic characteristics of spectrum have been explored by other researchers. Herter [15] finds that "[u]nlike hard minerals or petroleum, the electromagnetic spectrum is not depletable; it is always available in infinite abundance except for that portion which is being used. When that portion of the electromagnetic spectrum is not in use, it is instantly renewable ... [s]oils or forests are also renewable but frequently at a price ... spectrum has been called a "limited" natural resource because, given present technology, there is only a finite portion available for beneficial uses at any one time." Shelansky and Huber [16] observe that "there is no such thing as spectrum," which is a provocative way of saying that "radio is an invented good, which is highly dependent on technology." [17].

We concur with previous scholars [15], [17] and find that spectrum best fits the "Common Pool" type of good because it exhibits the properties of subtractability of use and difficulty of exclusion under current technology. The physical properties of spectrum give rise to the subtractability of use. When a person emits energy into a particular piece of electrospace, it raises the noise level for other possible users. Following the Shannon-Hartley Theorem, an increase in noise decreases the available channel capacity ceteris paribus. Thus, we conclude that subtractability of use for spectrum is best classified as being high for the purposes of Ostrom's goods typology. ${ }^{11}$

As to the other dimension, we assert that it is relatively difficult to exclude an arbitrary user from the use of most regions of electrospace. WiFi access points may use passwords and CMRS systems may use various forms of encryption and access control built into the multiple access protocols, but these only serve to exclude non-subscribers from using their radio systems, not the spectrum. In the ISM bands, nonWiFi devices (e.g., Bluetooth, Zigbee, cordless phones) can compete with WiFi; likewise, cell phone and GPS jammers are readily available for purchase (though not legally so in many jurisdictions) in various bands and power levels. As well, the emergence of inexpensive and widely available software radios (e.g., GNU radios, USRPs) that can be programmed to the user's needs can emit radio energy over a wide range of frequency bands (whether legal or not). Yet another example of the difficulty of exclusion can be found in the jamming of radio signals that was common during the Cold War [17].

We recognize that subtractability and excludability in spectrum are intimately connected with technology. ${ }^{12}$ For example, the case can be made that ultrawideband (UWB) is practically not subtractable because the loss in capacity is so small that

\footnotetext{
${ }^{11}$ Better radio technology and management frameworks expand the range of sharing options, expanding options for co-existence among diverse systems and users, and thus reduce subtractability of use.

${ }^{12}$ As we explain further below, technology works in concert with policy and other factors in the ecosystem. For example, tight radio certification requirements coupled with strong enforcement make it easier to exclude, regardless of the state of radio technology.
}

it may not be measurable; and smart antenna technology allows for spatial multiplexing that could make subtractability insignificant. Similarly, excludability depends on the cost and efficacy of detection, identification and enforcement techniques and technologies. Highly effective and inexpensive enforcement approaches could result in de facto excludability even if this is not so in the abstract. The fact that radio technologies and other factors of the radio ecosystem may evolve suggests that it is best to view spectrum as a CPR, where the extent of excludability and subtractability of use may vary with a host of factors in the ecosystem (not just, technology) and may be responsive to the design of the spectrum management regime.

\section{Alternatives FOR SPECTRUM GOVERnANCE}

Broadly speaking, spectrum sharing involves a redistribution of rights among an enlarged group of stakeholders [18]. ${ }^{13}$ This points in general to a need for revised governance, which refers to "any mode of co-ordination of interdependent activities" [20]. This coordination includes the (dynamic) distribution of rights among stakeholders and mechanisms for enforcing those rights [11], [21], [22].

Much of the debate over spectrum management has focused on whether spectrum should be treated more like private property, governed by exclusive-use licenses where sharing options may be limited by the licensee; or as an unlicensed commons, where access is open [23], [24]. With a commons, there is the risk that aggregate usage will be excessive since individual users may fail to take into account the adverse effects of their usage on others (i.e., subtractability of use); and because users cannot be excluded, a Tragedy of the Commons may result. We follow Lehr [25] in claiming that the dichotomy between exclusive use and commons is a false one. With private property, there is a risk of inefficient (or nonexistent) markets precluding efficient resource assignments. ${ }^{14}$ Moreover, Smith [27], Ostrom [11], Fennell [28] and others (e.g., [29]) argue that many options for governing common pool resources, such as spectrum, exist that successfully avoid the "tragedy of the commons".

\section{A. Common pool resources and governance}

CPR scholars have shown that common pool resources are amenable to a range of governance approaches [11], [22], [30]. The earlier literature that classified goods as private or public equated private goods with (decentralized) market governance and public goods with (centralized) state governance, as if the choice were binary. CPR scholars recognized that this did not fit many resource cases well and that the best governance

\footnotetext{
${ }^{13}$ Agrawal and Ostrom [19] note that "decentralization is also synonymous with redistribution of power, resources, and administrative capacities through different territorial units of a government and across local groups. Thus, decentralization can be seen as a strategy of governance, prompted by external or domestic pressures to facilitate transfers of power closer to those who are most affected by the exercise of power.'

${ }^{14}$ Excludability and the other features that give rise to efficient markets (e.g., liquid supply and demand, low transaction costs, etc.) cannot be presumed to simply exist [26]. The CPR framework emphasizes the extent to which excludability and subtractability in use exist on a continuum.
} 
systems are typically polycentric, which means that there are multiple centers of decision-making control or influence that may partially overlap in scope or hierarchy and interact with each other in complex ways that evolve over time.

Thus, contrary to the predictions of earlier theory, in analyzing the municipal governance of police, water and other public good resources, CPR scholars found that there were benefits from a polycentric approach, but the precise factors that predict what works best are context dependent [11]. ${ }^{15}$ For example, when the numbers of resource users are small, then an open commons type of governance structure, in which users own the resource collectively, may work best; whereas when the numbers of resource users gets large, mechanisms that are closer to more traditional private property rights regimes may be needed. For intermediate cases, polycentric governance may be most appropriate. In this last form of governance, stakeholders distribute the rights amongst themselves and develop decentralized approaches to enforce that rights structure. This is often a dynamic structure because technology, resource characteristics, resource demand, etc. may change over time.

Another outcome of the CPR literature is a more nuanced notion of property rights. Classifying users into different broad types according to their role in resource governance and use has proven helpful in understanding polycentric resource governance since a heterogeneity of rights holders exists. More broadly, it has led to a recognition that the notion of "property rights" actually refers to a bundle of rights. For many natural resources, Schlager and Ostrom [30] proposed the rights structure in Table II. ${ }^{16}$ The first two rights (i.e., Access and Withdrawal) can be considered usage rights which relate to the operation of the resource system, while the remaining three are referred to as collective action rights, which refer to the design of the rights system. ${ }^{17}$ In Table II, there is a natural hierarchy of possible stakeholders with those with the least rights being "entrants" and those with more collective action rights having more decision-making control.

As argued in [18], the bundles of rights in spectrum depend on the usage paradigm. In the exclusive use paradigm, the use and collective action rights are assigned to the license holders. The license holders are therefore viewed as "Full Owners." Access rights (i.e., the right to receive) depends on the application type - in broadcasting, we may have "Authorized Entrants" who have receive but not transmit rights. As spectrum sharing is introduced, we add a class of

\footnotetext{
${ }^{15}$ Earlier predictions were that to the extent that public goods aspects of such resources as police, water, or fisheries dictated a need for state control, such control should be centralized to avoid duplication of authority In contrast, case studies of real world police forces, water management, or fishery management systems have found that a mix of decentralized control allocated to local users, with some agency for centralized control often works better in practice. Such systems are more flexible and adaptive, and better able to adjust to differences in local circumstances.

${ }^{16}$ These notions have been generally applied to international spectrum assignment [17] albeit not at the same level of granularity.

${ }^{17}$ Management rights refer to the design of the rights by which the resource is used and managed; whereas Exclusion rights refer to the design of the rights as to who has access to the resource. The Alienation rights refer to the rights to transfer any of the other rights.
}

\begin{tabular}{|l|l|l|l|l|l|}
\hline & $\begin{array}{l}\text { Full } \\
\text { owner }\end{array}$ & $\begin{array}{l}\text { Prop- } \\
\text { rietor }\end{array}$ & $\begin{array}{l}\text { Auth. } \\
\text { claimant }\end{array}$ & $\begin{array}{l}\text { Auth. } \\
\text { user }\end{array}$ & $\begin{array}{l}\text { Auth. } \\
\text { entrant }\end{array}$ \\
\hline \hline Access & $\mathrm{X}$ & $\mathrm{X}$ & $\mathrm{X}$ & $\mathrm{X}$ & $\mathrm{X}$ \\
Withdrawal & $\mathrm{X}$ & $\mathrm{X}$ & $\mathrm{X}$ & $\mathrm{X}$ & \\
Management & $\mathrm{X}$ & $\mathrm{X}$ & $\mathrm{X}$ & & \\
Exclusion & $\mathrm{X}$ & $\mathrm{X}$ & & & \\
Alienation & $\mathrm{X}$ & & & & \\
\hline
\end{tabular}

TABLE II

DISTRIBUTION OF RIGHTS BY USER TYPE

"Authorized Users" as well. These users may be authorized by the government or through explicit consent (the "participation" scale in Figure 4). If it is through consent, the "Authorized Users" may be better classified as "Authorized Claimants" since they may have some collective action rights.

We can contrast this with the ISM bands, which use an open access governance paradigm. Here, most collective action rights are effectively held by a licensing authority or government and the access (receive) and withdrawal (transmit) rights are shared equally by all users. As we explain further below, even in such circumstances, governance may be feasible.

\section{B. Spectrum governance}

The literature has paid considerable attention to the virtues of both commons as well as property-based approaches to spectrum governance. In contrast, relatively little attention has been paid to the possibility of polycentric governance of spectrum, although two studies address this in particular [17], [31].

To illustrate this point, consider different approaches to the de facto governance of WiFi bands. Figure 1 shows channel usage in a condominium complex. In this complex, each owner installs and maintains their own WiFi system, which results in considerable contention for the available channels. That is, governance is "open access" and spectrum users do not coordinate with each other. But other forms of governance are possible. For example, the channel usage in figure 2 is from a condominium complex where WiFi is provided by the association. This results in a more managed user experience despite being situated near other condominium complexes. The result is similar to what might be found in a hotel (Figure 3), where the ISM bands are (mostly) governed by the property owner. What these examples illustrate are the technical benefits from coordinated governance of the unlicensed access points when congestion becomes an issue.

Note that the "governance" of unlicensed bands is subject to significant limitations in the US [18]. The recent case involving Marriott [32] illustrates the problem: was Marriott blocking other WiFi access points to provide a better experience for users on its premises or unfairly discriminating against non-affiliated access points (for profit)? The FCC's OTARD rules [33] significantly limit the ability to manage this shared resource, whether through the lens of Ostrom or Coase. However, in the presence of congestion, more flexible 


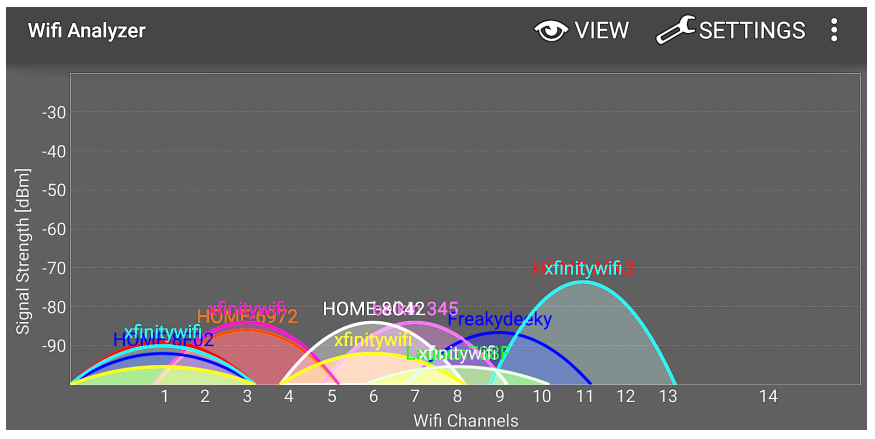

Fig. 1. WiFi channel occupancy in an unmanaged condominium complex

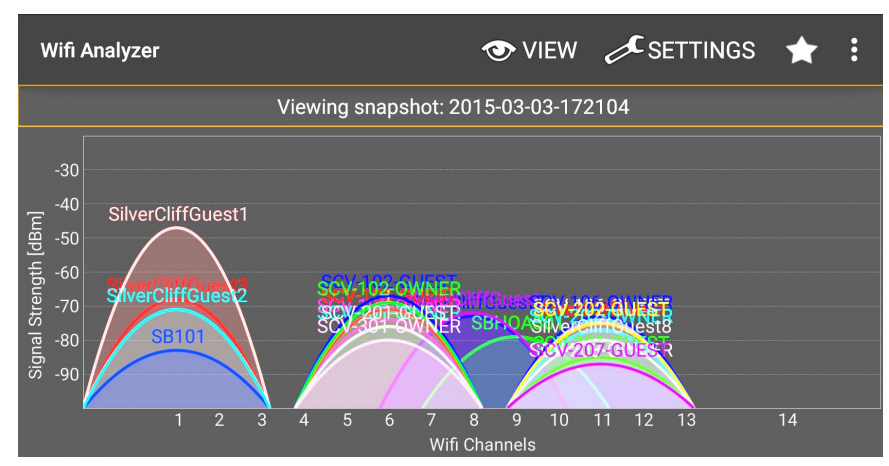

Fig. 2. WiFi channel occupancy in a managed condominium complex

spectrum governance should be able to enhance the experience for all users.

Spectrum sharing introduces new bundles of rights that vary with the sharing model. Figure 4 highlights three dimensions along which sharing may be differentiated: cooperation/coordination, hierarchy and participation. The cooperation/coordination dimension refers to the way in which sharing is achieved between a primary license holder and the spectrum entrant (primary/secondary users). Cooperative sharing involves explicit coordination between the sharing parties; whereas non-cooperative sharing is equivalent to opportunistic sharing (i.e., the secondary user may only use the spectrum in so far as such use does not interfere with the primary user). The hierarchy dimension refers to the extent to which there are multiple tiers of rights holders with different

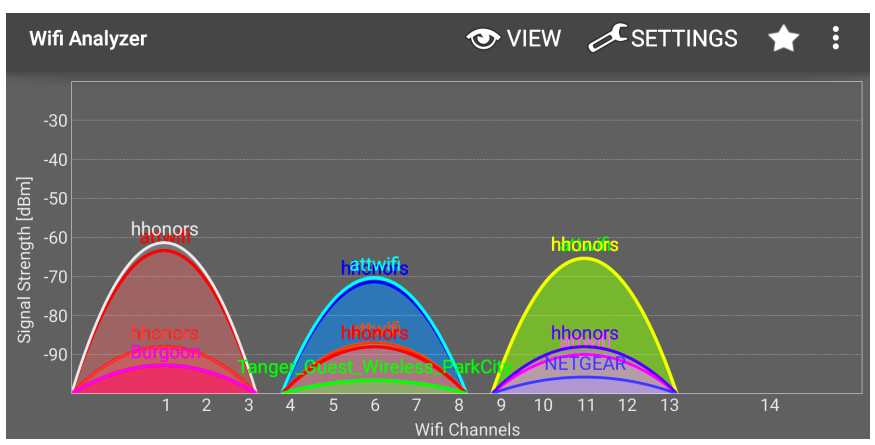

Fig. 3. WiFi channel occupancy in a hotel

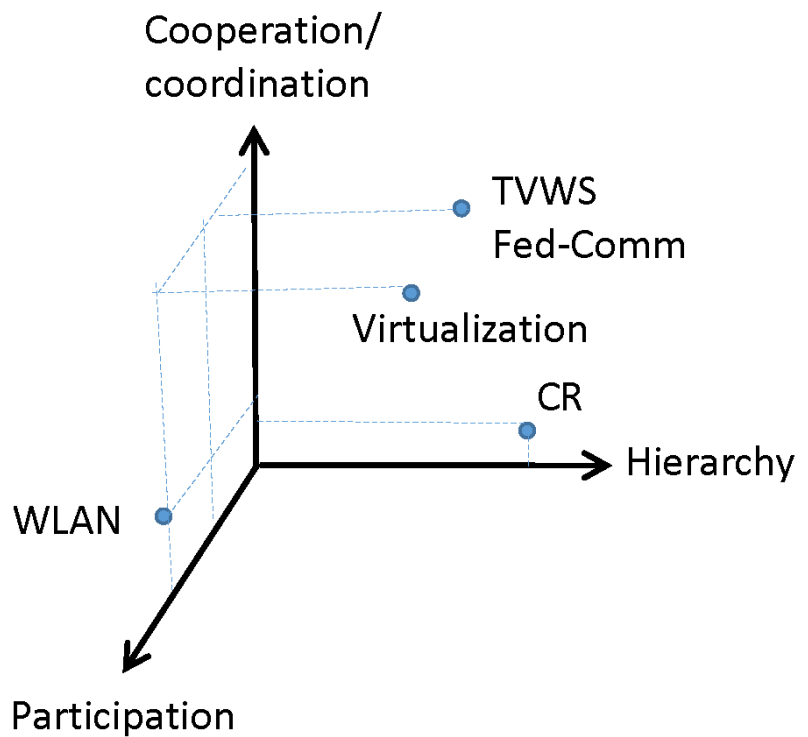

Fig. 4. Typology of spectrum sharing

levels of priority, and within each tier, multiple holders with symmetric rights. For example, in the exclusively licensed PCS bands, the cellular licensee has primary access rights. UWB users operate as secondary users in the noise floor in bands they share, while TVWS devices must avoid interfering with TV broadcasters. Typically, entrants are thought to have secondary rights to incumbents; but that is a matter of policy choice. ${ }^{18}$ Finally, the participation dimension refers to the extent to which radio operators voluntarily agree to share spectrum. Low participation implies a de jure spectrum sharing obligation that requires the operators to share.

In this framing, TVWS is a case of low participation (because the right to share broadcast spectrum is mandated by the FCC), high cooperation (because sharing is mediated by a database), and high hierarchy (since TVWS devices operate as secondary to TV broadcasters). By way of contrast, Cognitive Radio (CR) sharing is also low participation and high hierarchy, but is low coordination since individual CR radios are assumed to adapt their behavior without requiring explicit coordination or cooperation from the primary incumbent systems. Wi-Fi WLANs are high participation (because radio operators need to voluntarily agree to share the spectrum since neither the existing technology or regulations provide coordination mechanisms (so low cooperation/coordination), and low hierarchy since all Wi-Fi radios have same level of priority. ${ }^{19}$

\footnotetext{
${ }^{18}$ For example, public safety might be given "lights \& siren" priority access rights to a new band.

${ }^{19} \mathrm{Wi}$-Fi does have limited technical support for cooperative sharing. For example, during initial start-up, Wi-Fi radios attempt to select an unoccupied channel. Unfortunately, having selected a channel, Wi-Fi radios may not reoptimize their channel selection when other access points come on line. Wi-Fi radios also lack the ability to adjust their power-levels to better accommodate additional access points.
} 


\section{Polycentric governance of spectrum}

Wormbs [31] examined European broadcasting in the 1920s from the perspective of CPR governance. She showed that the international radio coordination efforts could be mapped to Ostrom's factors of successful polycentric governance. In this case, sanctions for violating the agreed upon rules worked effectively through the mechanism of "regulation by information." [34]

Wormbs argues that the "logic of demand and supply has formed the present discourse on how to use the radio spectrum, which in turn might limit our understanding of how this resource can be efficiently used." Note that her analysis was performed in an era when technology was relatively static. ${ }^{20}$ Today's context is characterized by rapid changes in technical capability and cost. These changes may lead us to intriguing possibilities for the future of wireless networks.

A more comprehensive view of the futures for wireless networks that have been proposed would be beyond the scope of this paper, though it might be useful to briefly consider one. Doyle et al. [35] articulate a future wireless environment where service providers assemble the resources they need from the resource owners through the mechanism of spectrum virtualization. Such a future would have to define a new mode of sharing (high participation and cooperation with clearly defined rights relationships) and novel arrangements of rights, which could benefit from polycentric governance of wireless resources. ${ }^{21}$ While considerable research and development is needed to make such a vision a reality, it seems reasonable to work to ensure that SAS designs that are being developed today should not preclude these kinds of rights distributions or governance arrangements.

Agrawal [22] reviews the CPR literature and summarizes the factors that enable sustainable and efficient polycentric governance. As noted, CPR scholars conclude that a wide range of factors need to be considered and these are not easily reduced to a simple set of requirements and recommendations. The right framework depends on a number of factors. Agrawal collected the facilitating conditions of successful, sustainable decentralized governance systems of common pool resources described by the leading CPR scholars. These are summarized in Table III. Agrawal makes it clear that it is not necessary for all of these conditions to hold for successful decentralized governance to exist.

With this background in mind, let us explore when polycentric governance of spectrum might be possible. While this is an empirical question in the end, we can make some qualitative assessments. To do so, let us consider the categories from Table III. Of these, the first three define the domain

\footnotetext{
${ }^{20}$ Interestingly, Wormbs shows the powerful effect of the change in receiver technology (crystal radios to vacuum tube sets) on perceived interference. This shows how technology can change the outcomes of governance decisions even when resource allocation strategies are relatively static.

${ }^{21}$ Policymakers have discussed alternative models for dividing electrospace into bundles of Spectrum Usage Rights that could be coordinated, prioritized, and traded voluntarily on spectrum exchanges. For a discussion of vision of Spectrum Usage rights, see [36]-[38]
}

\begin{tabular}{|l|l|}
\hline \multicolumn{1}{|c|}{ Category } & \multicolumn{1}{c|}{ Characteristic } \\
\hline \hline Resource system & 1. Small size \\
characteristics & 2. Well-defined boundaries \\
\hline Group characteristics & 3. Small size \\
& 4. Clearly defined boundaries \\
& 5. Shared norms \\
& 6. Social capital \\
& 7. Appropriate leadership \\
& 8. Interdependence among members \\
& 9. Heterogeneity of endowments \\
10. Homogeneity of interests \\
\hline Relationship betw. resource & 11. User \& resource location overlap \\
$\&$ group characteristics & 12. High dependence on resource \\
& 13. Fairness in allocation of benefits \\
\hline Institutional arrangements & 14. Simple \& easy to understand rules \\
& 15. Locally devised access \& mgt rules \\
& 16. Ease in enforcement of rules \\
& 17. Graduated sanctions \\
& 18. Availability of low-cost adjudication \\
19. Accountability of monitors to users
\end{tabular}

TABLE III

FACILITATING CONDITIONS FOR CPR GOVERNANCE

of applicability (i.e., frequency bands, geographic area) and the remaining four are pertinent to technical and institutional design choices in SAS systems. The literature in infrastructure studies (e.g., [6]) makes it clear that these choices are intimately linked. These design choices will be the focus of the subsequent sections of this paper.

1) Resource system characteristics: In the case of spectrum, there are multiple ways one might define the resource. De Vany [2] and Matheson [3], [4] . This is partly the case because the received signal strength of electromagnetic signals varies randomly. ${ }^{22}$

The other characteristic of relevance is "small size." This is difficult to assess as it depends on the application and the frequency band in question in addition to technical parameters such as antenna type and height as well as transmit power level and receiver sensitivity. That said, in the frequencies of interest to CMRS, the standard Metropolitan Statistical Area (MSA) may be considered small enough. For the ISM bands, small size almost certainly applies. In the AM radio band at night, it would be difficult to make the case for "small size" as long range propagation is typical.

2) Group characteristics: According to CPR research, successful polycentric governance is most likely to be successful when the size of the group is small, when the boundaries of the resource are well defined, when there are favorable social conditions (e.g., shared norms, social capital, etc.) and when

\footnotetext{
${ }^{22}$ This is clearly dependent on the frequency band in question, as some bands may be subject to Rayleigh fading (for example) and others may not. Measurement based propagation models have been successful at determining the expected value of received signal strength in many bands.
} 
the group members are interdependent with a heterogeneity of endowments and a homogeneity of interests. As with resource system characteristic, much of this depends on the particulars of sharing. However, we can make some observations that apply in general.

In spectrum sharing cases of interest, that is, those that do not involve very sparse user populations where demand for spectrum access is lower than supply, it can be said that group members are interdependent on one another since sharing responsibly means managing mutual co-channel and adjacent channel interference. While resource boundaries are not necessarily well defined, in many proposed cases they overlap with population boundaries, that is, neighborhoods and towns.

Moving on to some particular cases, let us first consider the case of Federal-commercial sharing in the $1695-1710 \mathrm{MHz}$ band. The group is small in each locality. The relevant boundaries are defined by exclusion zones. The group members are interdependent in the sense that mutual interference is possible. At this point, there is little or no social capital because spectrum sharing is new. Over time, this would likely change. In the $3.5 \mathrm{GHz}$ band, the relevant group is potentially larger because of the presence of GAA users. This would make polycentric governance of the resource as a whole unlikely. However, at the proposed power levels for GAA, the signal would not propagate far so that meaningful neighborhood level governance of GAA bands could succeed, just as it can in the case of $\mathrm{WiFi}$ in condominium complexes.

3) Relationship between resource and group characteristics: [22] reminds us that critical factors for successful polycentric governance of CPRs must consider not just the group and resource characteristics but also the relationship between the two. For example, studies have pointed out that successful cases of polycentric governance occur when users are highly dependent on the resource and when there is a overlap between the user group and the resource. Finally, there should be a perception on the part of group members that the benefits of the resource are allocated fairly.

For many frequency bands, spectrum use is predominantly a local affair. ${ }^{23}$ Indeed, cellular network architectures have exploited this fact to increase system capacity through spatial frequency re-use. Thus, the area of interest in sharing, say, in the $1695-1710 \mathrm{MHz}$ band is the region near the boundaries of the exclusion zones. The user groups (spectrum incumbent and entrants) are both dependent on this resource and their resources (cell sites, earth stations, etc.) overlap the resource boundary.

4) Institutional arrangements: Institutional arrangements refer to the social and legal frameworks within which CPR governance exists. Williamson [21] summarizes these from the point of view of institutional economics. Agrawal summarizes the key factors for successful polycentric governance to be simple and easy to understand rules, locally devised access

\footnotetext{
${ }^{23}$ While some frequencies can propagate large distances, many of commercial interest are limited to line-of-sight (LoS) propagation modes.
}

and management rules, ease in enforcement of rules, graduated sanctions, availability of low-cost adjudication, and the accountability of monitors to users. Sanctions refer to penalties for violation of the rules and the monitors are the people or entities who are involved in the enforcement of the rules. Note that the monitors may be the users themselves or a third party.

This category of factors focuses on access and enforcement rules. Schlager and Ostrom [39] argued that different types of users have different roles in the governance of a CPR system, which they codified in Table II.

The distribution of rights depends on the mode of sharing. Sharing modes that rank high on the hierarchy scale (see Figure 4) would have fewer collective action rights granted to spectrum entrants than those that are low on this scale (i.e., which are more peer-to-peer). Similarly, we would expect greater reluctance to negotiate rights distribution when participation is low (i.e., under de jure sharing). This would suggest institutional designs to foster social capital and protect the positions of more poorly situated participants. ${ }^{24}$

This category speaks to the need for ex post enforcement as part of a broader enforcement strategy, which has also been argued in [40]. Cost effectiveness, transparency, ease of enforcement and graduated sanctions are important. Graduated sanctions imply flexibility in responding to rule violations. Doing so cost effectively remains a challenge. In the domain of spectrum, this might call for a kind of sensor network to support ex post adjudication [41].

In the end, CPR research suggests that local determinations of rights, rules and enforcement should be possible for efficient resource management. The definition of "local" is arbitrary and depends on what makes sense from the resource and user point-of-view rather than being determined by a distant central authority. ${ }^{25}$

5) Relationship between resource and institutional arrangements: The institutional rules discussed above do not exist independently of the resource being governed. In fact, the CPR literature suggests that a close match exists between the resource rules and the associated institutional arrangements. Polycentric governance also demands attention to sustainable resource management. Since spectrum is infinitely renewable, sustainable resource management means that the kind of stewardship required of, say, a fishery or forest is not necessary. Having said that, numerous industry observers have noted the threat posed by the generally higher noise environment facing wireless systems today. This increased noise is due to many factors, including the increased distribution and use of electrical devices, many processor-based devices (including MP3 players, tablets, etc. as well as devices with embedded processors) that radiate small amounts of electromagnetic

\footnotetext{
${ }^{24}$ These might be spectrum entrants, but they could just as well be weaker primary users. In the case of the $1695-1710 \mathrm{MHz}$ band, the argument could be made that the spectrum entrants (CMRS operators) were positioned more strongly than the license holder (NOAA).

${ }^{25}$ Local is italicized because it is not limited to spatial (geographic) dimensions. It may also refer to nearness in time, technology, usage, or some other characteristic of the sharing context.
} 
energy, imperfect and out-of-calibration filters on communications devices, etc. These devices conspire to reduce the useful capacity of radio spectrum, so some kind of general resource stewardship may be desirable.

6) External environment: Agrawal [22] suggests an array of external factors, such as the availability of low-cost exclusion technology. He, like Williamson [21], emphasizes the importance of a broader institutional context. In the case of CPR, it is important to have support from central governments for the local governance authority, and that supportive external sanctioning institutions, especially for enforcement, to exist.

7) Nested levels of appropriation, provision, enforcement and governance: Ostrom [11] indicates that a local polycentric governance framework can exist as part of a nested governance system. This allows for coordination and governance at various scales. For spectrum, this suggests that explicit institutional governance relationships exist. The US has long had a multilevel system of communications regulation [42] which could be viewed in this manner. In spectrum, the FCC has delegated governance authority to the amateur radio community for its bands [18]. Applying this to spectrum sharing, let us consider the $1675-1710 \mathrm{MHz}$ bands. The NOAA earth stations in Miami and Honolulu have terrain and population profiles that are quite different from one another [43]. Thus it seems reasonable to imagine that a local approach to spectrum sharing could emerge that is specific to the local circumstances.

Many of the proposals for SAS already anticipate the desirability of this feature in their designs. ${ }^{26}$. These are reflected in the FCC's Report and Order and Further NPRM on the $3.5 \mathrm{GHz}$ band [44].

This nesting may also extend internationally. The ITU$\mathrm{R}$ serves to allocate spectrum use among countries. Similarly, spectrum coordination takes place among the member countries of the European Union. Further, regions near national borders may require specific bi-lateral spectrum sharing agreements. Thus, local governance of spectrum resources exists in a rich context of national and international spectrum governance arrangements.

\section{SASS AND SPECTRUM GOVERNANCE OPTIONS}

Many of the emergent forms of spectrum access will rely on the use of database-driven Spectrum Access Systems (SASs). While there is no consensus as yet on the design or structure of such systems, we will use the one from the Finnish LSA trial [45] as a working model, reproduced in Figure 5, since it has been demonstrated to work in actual practice. Note that other models are emerging as well (see, for example, Marshall [46] and Sohul et.al. [47]).

When a spectrum entrant wishes to transmit, it queries the LSA/ASA controller. This controller decides whether or not to permit the entrant's transmission based on a database, the LSA/ASA license framework, which is populated and maintained jointly by the regulator and the incumbent.

\footnotetext{
${ }^{26}$ See, for example the presentation of the FCC SAS workshop, at http: //www.fcc.gov/events/35-ghz-spectrum-access-system-workshop
}

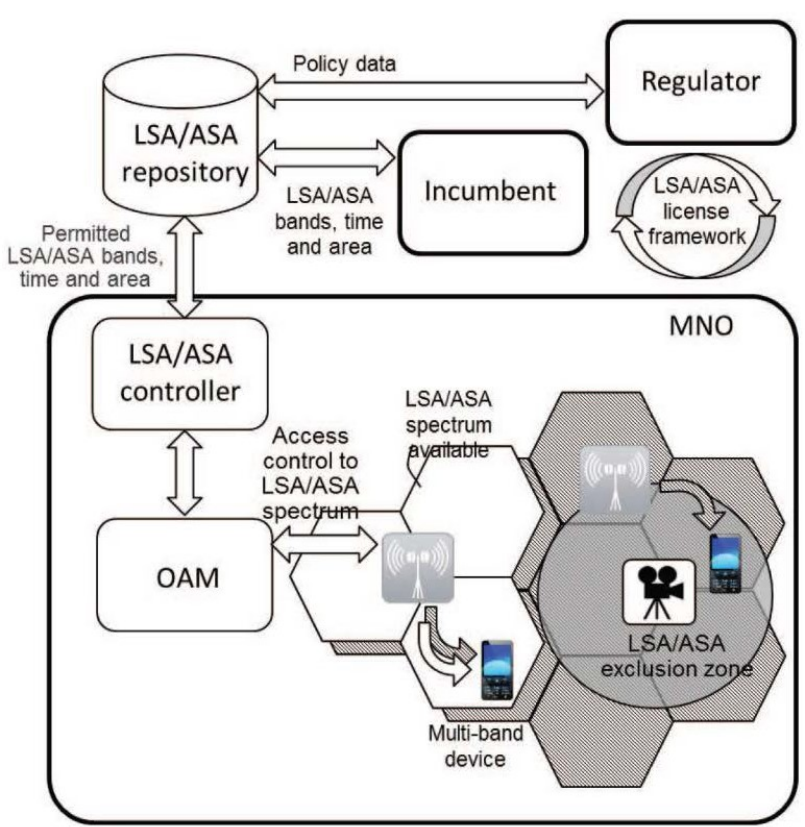

Fig. 5. Prototype SAS (from [45])

We note that this implementation embodies a particular rights distribution and governance structure. However, it is not clear what governance procedures for this database are. For example, we do not know what the particular rights of each party are and how they collaborate to determine the contents of the database. Also unspecified are dispute resolution mechanisms and procedures for revising the content of the database.

From the point of view of polycentric governance, it is difficult to see how that this architecture allows for meaningful governance of the resource system, which, in this case, is the licensed spectrum to be shared. The spectrum entrant is weakly situated politically and technically as the only way to influence the spectrum sharing operations is to influence the regulator. There are theories of regulation (e.g., the "capture theory") that would suggest that the entrant would find it difficult or impossible to engage in meaningful governance of this resource. ${ }^{27}$ Furthermore, there is no mechanism for accountability built in to the framework, which makes enforcement of the spectrum sharing framework difficult (e.g., is spectrum being shared as intended?).

Applying Agrawal's framework (Table III), we focus on characteristics related to institutional arrangements, since that is the locus of governance. These characteristics require transparency of the rules: Are they simple and easy to understand (\#14)? Are the rules locally devised (\#15)?). Perhaps the regulator in the prototype SAS publishes the rules, however in a potentially dynamic environment, it is difficult to make the case that published rules would be current or useful. Another group of characteristics focus on enforcement: Is it easy to

\footnotetext{
${ }^{27} \mathrm{~A}$ discussion of theories of regulation is outside the scope of this paper See [48] or [49] for surveys.
} 
enforce the rules (\#16)? Are sanctions for violations graduated (\#17)? Is adjudication low cost (\#18)?). To the extent that access is strictly controlled by the SAS, it would be fair to say that enforcement is easy. However, if the entrant's radios violate the rules and thus encroach on the incumbent's electrospace, it is unclear how the system would respond. If it is by withdrawing the license, it is hard to say that the sanctions are graduated. What recourse do entrants have to such action? Appealing to the regulatory agency is not, generally speaking, a low cost adjudication approach. Finally, the table suggests that accountability of the "monitors" - that is, the entities enforcing the rules - is important (\#19). Outside of the vector of the regulatory agency, it is hard to find a mechanism for accountability in Figure 5.

Outside of the institutional arrangements, the CPR literature suggests a perception of fairness in allocation of benefits (\#13). If the spectrum entrants do not have some collective action rights (e.g., a management right), then it may be difficult to sustain an argument that benefits are being fairly distributed.

If polycentric governance of shared spectrum is to be enabled, the prototype architecture of the SAS could be modified as shown in Figure 6. Note that the technical aspect of operation does not change in a significant way; this system is now situated to reflect a range of possible social and institutional contexts. This architecture adds the following:

- A governance process that feeds the SAS repository that controls how actions are taken.

- A database that records the decisions of the controller. This database serves as feedback to the governance process so that the rules for access and use can be updated based on past experience. It also enables accountability, which supports the governance process and can help build social capital. It also provides statistical data to spectrum entrants that they can use in their decision process.

- New stakeholders and participants in the governance process. It is not required that all participate, nor is this list necessarily complete. We propose that this list is suggestive of how to design a SAS that could support polycentric governance. The participants are:

- Incumbents These are the license holders, as included in Figure 5.

- Regulator This was included in Figure 5.

- Spectrum Entrants The entities that will share the spectrum now have a voice in determining the access rules and observing the operation of the SAS.

- The Public/NGOs For the purposes of accountability, there will be a role for public participation in the governance process. This might end up being NGOs because of the technical nature of spectrum governance.

- Regional coordination Given that polycentric governance may be nested levels, an ability for regional or higher layer coordination must be included.

- SAS providers SAS providers are a stakeholder that should have a voice in the governance process.

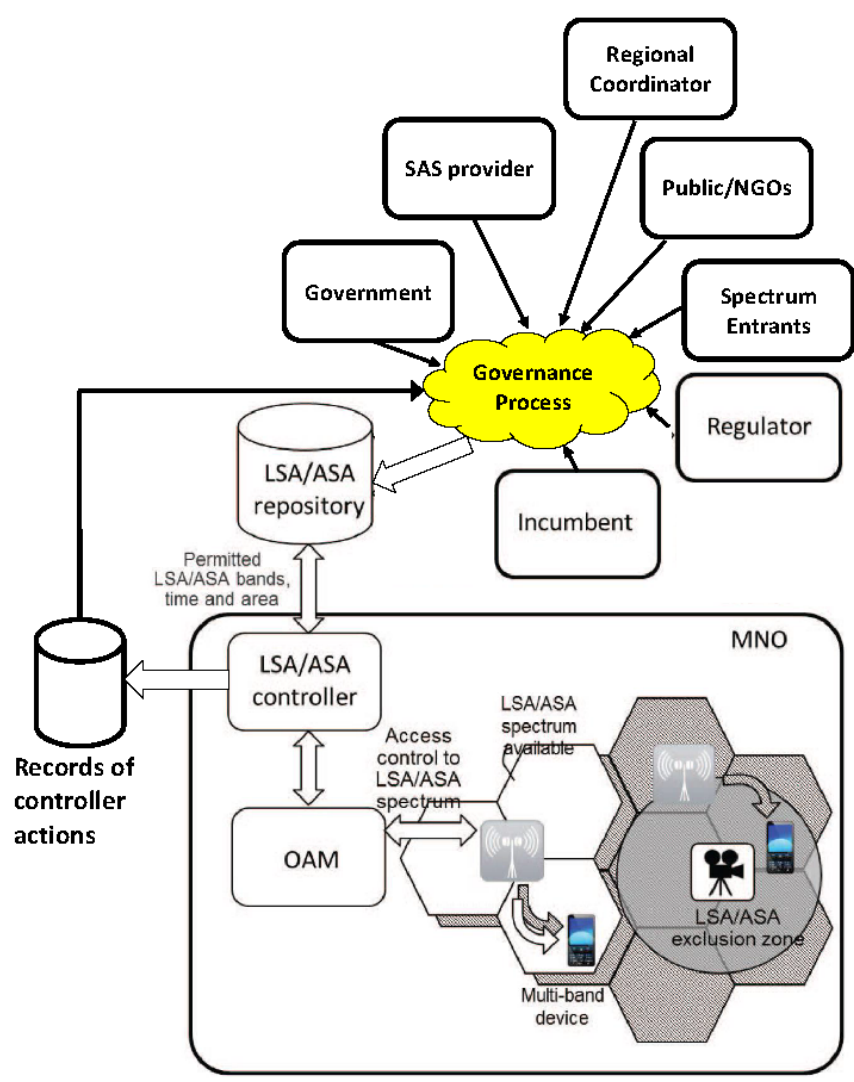

Fig. 6. Modified prototype SAS

- Government Here, the government refers to the policy/political aspect of government rather than the operational aspect represented by the regulator.

This modified design would not change the resource or group characteristics. These changes would facilitate a dynamic sense of fairness among the stakeholders as well as accountability of the implementors (SAS Operators) to the stakeholders. Thus, it addresses some of the limitations of the initial architecture with regard to possible polycentric governance of the spectrum. We reiterate that such a revision does not require polycentric governance, it merely enables it where it makes sense.

Note that the "governance process" is deliberately not clearly defined. This is not an oversight, since it depends on which collective action rights are assigned to which groups, and what decision-making process is agreed upon by the groups. These determinations depend heavily on the particulars of the sharing arrangement.

To make this more concrete, let us consider an LSA/ASA approach as proposed for the $3.5 \mathrm{GHz}$ band in the US. This band envisions a hierarchy of rights such that the incumbent, US military radars, hold superior usage rights over the Priority Access (PA) users, both of whom have superior usage rights 
over the General Authorized Access (GAA) users. ${ }^{28}$ This usage rights structure was determined ex ante.

Note that the usage rights hierarchy does not necessarily mean that collective action rights follow the same hierarchy. In fact, the CSMAC and FCC processes for the $3.5 \mathrm{GHz}$ bands are, in fact, shared governance in that the rules for access (management rights) and exclusion (exclusion rights) are being worked out in a multi-stakeholder group that includes representatives from the FCC (the independent regulatory authority for commercial spectrum users), other government agencies, industry stakeholders, and representatives from academia and other interested groups.

Polycentric governance suggests that the rules be developed locally as part of a broader system (nested levels of governance, from Table III). For the $3.5 \mathrm{GHz}$ band, this could also make sense. For example, in regions where there are no military radars they assert no usage rights, so this becomes a two level usage rights regime, since the absence of usage rights could suggest limited (if any) collective action rights. Furthermore, the varying topography of the coastal regions suggests that highly localized adaption of usage rights might be practical.

The $3.5 \mathrm{GHz}$ case makes accountability (\#19 in Table III) more challenging, since the military often requires a measure of confidentiality for their operations. GAA and PA users would need a way to ensure that the rules were being enforced so that lower priority users would be confident that their access is not to be blocked without a justification grounded in the ex ante rules (e.g., for political reasons), which is to say to promote fairness (\#13). Given the sensitivities of the data, the governance process would have to be used to find a suitable solution to this dilemma.

We assert that the governance process itself is part of the infrastructural development of providing access to radio spectrum. As we have seen, SASs are technology in the making, and have yet to become settled [50]. Because SAS will be built upon an installed base of a static, legacy system, and because it embodies a variety of standards (and sometimes conflicting conventions), it carries with it a need for combinatory approaches to governance [9], [51]. We offer a combinatory approach to the socio-technical aspects of design, primarily through polycentric approaches to governance. As mentioned earlier, we propose employing a social-technical perspective to the development of SAS governance through a polycentric perspective. By adding elements to the modified SAS prototype from [31] (entrants, public accountability, regional coordination, and architecture providers) we aim to yoke socio-technical elements to the technological momentum of infrastructural development of SAS [50].

\footnotetext{
${ }^{28}$ It should be noted that this prioritization is a matter of policy choice, and may change in the future. Commercial licensees, once granted PA licenses, will expect to have interference protection from both incumbent, GAA, and other PA licensees in the future. Expectations of what rights imply will evolve with the market and technology, and the policy framework needs to be flexible to adapt.
}

\section{SAS AS AN EXERCISE IN POLYCENTRIC GOVERNANCE}

Much of the prior discussion has focused on how the different factors that arise in the design of CPR governance would apply to the design of a SAS. It is also important to understand the SAS as an exercise in polycentric governance. The challenge confronting spectrum managers is to effect a wholesale transformation of the management paradigm from a status quo that is static, inflexible, and uninformative to one that is dynamic, flexible, and informative; to complete the transition from a legacy regime based on centralized $C \& C$ to one that is more market-based (while recognizing that means different things to different groups of stakeholders). The more distributed, multidimensional design of polycentric governance systems will assist in making this transition. This implies having multiple SAS that may be integrated and interoperate (to whatever extent is needed) more closely over time as collective learning accrues. Having multiple SAS databases (for different bands, administered by different entities, with possibly partially over-lapping jurisdictions) may facilitate the experiments in collective learning. Best practice designs may emerge over time.

More directly, the ability of the SAS to embrace dynamic rights assignments as a core goal will enable the SAS to serve as a platform for evolving rights assignments, where the evolution may occur at multiple time scales and along multiple dimensions. For example, the technology of the SAS should be amenable to upgrading of exclusion zone modeling techniques and capable of taking advantage of sensor information as such infrastructures evolve and enable more real-time management of the spectrum. While today's regulatory community is focused on expanding spectrum access for commercial mobile broadband services, tomorrow's challenges may be different and the SAS ought to be able to adjust to those new needs more flexibly.

Finally, the SAS will be a core component of the polycentric enforcement apparatus that will make whatever rights regime we adopt credible and effective. The SAS will accomplish this goal in multiple ways. It will provide an audit trail and repository for learning about spectrum usage that will be important for identifying sharing opportunities and constraints. It will provide a framework for managing the transition of new rules and regulations on a granular basis. Precisely how the SAS will accomplish these goals are important details that still need to be worked out, but having an appropriate vision for the SAS is an important starting point.

\section{A. Implementation Considerations}

The previous discussion provides relatively little specific guidance to builders of SASs. Space does not permit an exhaustive discussion of this and will therefore be a topic for a future paper. However, we can discuss this in general:

- There are process oriented aspects of polycentric governance, such as the determination and distribution of rights, that are of great importance to stakeholders and that may best be implemented through an API to a programmable policy engine. Similarly, the results database 
that is useful for accountability and statistical characterization of the sharing environment would benefit from an API. However, there are some possible national security concerns and competitive intelligence concerns that may require trusted post-processing to meet system objectives as well as private requirements.

- There are enforcement aspects of governance that are of considerable interest. Until now, the enforcement approach to SAS has been to emphasize ex ante, prophylactic measures [40]. But it is likely that interference will occur despite these measures, requiring ex post remediation. This will require a forensic capability to determine the cause of the interference event and a remunerative capability that is incentive compatible. ${ }^{29}$

- Implementing nested governance opens a set of challenges related to the synchronization and consistency of distributed databases, especially if some of the databases are subject to differing governance regimes. Lack of synchronization may be one of the causes of interference events, which should be considered in any forensic analysis.

\section{SUMMARY AND CONCLUSIONS}

The rapid technological changes in the wireless industry have driven substantial changes in system capabilities and cost, and there is no reason to believe that this will change in the foreseeable future. This almost certainly means that industry structure will adapt and take on forms that are unforeseeable today. Supporting many possible futures means having a SAS that is adaptable to evolving governance approaches. We have provided an example of what that might look like with a prototype SAS.

The CPR literature is based on case studies from many jurisdictions and socio-economic contexts. We use examples from the U.S. in this paper because they were more easily accessible to us, but it does not limit the applicability of the ideas to this country. As well, we have focused on the spectrum sharing systems that are of principal concern today, but that does not limit the applicability of CPR-based approaches to spectrum sharing either. For example, radio astronomy requires quiet spaces, which could also be negotiated via CPR approaches since they, too, are highly local in scope.

The literature on Common Pool Resources provides insight into what features may be desirable under diverse sustainable governance systems. We have argued that institutional and various other ecological factors should be explicitly reflected in the SAS design. Much remains to be worked out in terms of the details of the enabling or facilitating mechanisms.

\section{ACKNOWLEDGMENTS}

This work was supported in part by the U.S. National Science Foundation under Grants 1247546, 1443796, and 1345256.

\footnotetext{
${ }^{29}$ Sahai and his co-authors have written extensively about non-monetary consequences of interference events. See, for example [52].
}

\section{REFERENCES}

[1] Presidents Council of Advisors on Science and Technology, "Realizing the full potential of government-held spectrum to spur economic growth.” [Online]. Available: http://www.whitehouse.gov/sites/default/ files/microsites/ostp/pcast_spectrum_report_final_july_20_2012.pdf

[2] A. S. De Vany, R. D. Eckert, C. J. Meyers, D. J. O'Hara, and R. C. Scott, "A property system for market allocation of the electromagnetic spectrum: A legal-economic-engineering study," Stanford Law Review, pp. 1499-1561, 1969

[3] R. J. Matheson, "Principles of flexible-use spectrum rights," Communications and Networks, Journal of, vol. 8, no. 2, pp. 144-150, 2006.

[4] R. Matheson and A. C. Morris, "The technical basis for spectrum rights: Policies to enhance market efficiency," Telecommunications Policy, vol. 36 , no. 9 , pp. $783-792,2012$.

[5] M. B. Weiss, M. Altamimi, and L. Cui, "Spatio-temporal spectrum modeling: Taxonomy and economic evaluation of context acquisition," Telecommunications Policy, vol. 36, no. 4, pp. 335 - 348, 2012.

[6] G. C. Bowker, K. Baker, F. Millerand, and D. Ribes, "Toward information infrastructure studies: Ways of knowing in a networked environment," in International Handbook of Internet Research, J. Hunsinger, L. Klastrup, and M. M. Allen, Eds. Springer, 2010.

[7] L. Suchman, "Configuration," in Inventive methods: The happening of the social, C. Lury and N. Wakeford, Eds. Routledge, 2012, pp. 48-60.

[8] C. L. Borgman, P. N. Edwards, S. J. Jackson, M. K. Chalmers, G. C. Bowker, D. Ribes, M. Burton, and S. Calvert, "Knowledge infrastructures: Intellectual frameworks and research challenges," Deep Blue, 2013. [Online]. Available: http://hdl.handle.net/2027.42/97552

[9] S. L. Star and K. Ruhleder, "Steps toward an ecology of infrastructure: Design and access for large information spaces," Information systems research, vol. 7, no. 1, pp. 111-134, 1996

[10] T. P. Hughes, "The evolution of large technological systems," in The social construction of technological systems: New directions in the sociology and history of technology, W. E. Bijker, T. P. Hughes, T. Pinch, and D. G. Douglas, Eds. MIT Press, Cambridge, MA, 1987, pp. 51-82.

[11] E. Ostrom, "Beyond markets and states: Polycentric governance of complex economic systems," American Economic Review, vol. 100, pp. $1-33$, June 2010.

[12] H. Demsetz, "Toward a theory of property rights," American Economic Review, vol. 57, no. 2, pp. 347-59, 1966.

[13] P. A. Samuelson, "The pure theory of public expenditure," The Review of Economics and Statistics, vol. 36, no. 4, pp. 387-89, 1954.

[14] J. M. Buchanan, "An economic theory of clubs," Economica, vol. 32, no. 125 , pp. 1-14, 1965.

[15] C. A. Herter, "The electromagnetic spectrum: A critical natural resource," Natural Resources Journal, vol. 25, pp. 651-663, July 1985.

[16] H. A. Shelanski and P. W. Huber, "Administrative creation of property rights to radio spectrum," Journal of Law and Economics, vol. 41, no. S2, pp. 581-609, October 1998.

[17] C. Henrich-Franke, "Property rights on a cold war battlefield: managing broadcasting transmissions through the Iron Curtain," International Journal of the Commons, vol. 5, no. 1, p. 110 129, February 2011.

[18] L. Cui, M. M. Gomez, and M. B. Weiss, "Dimensions of cooperative spectrum sharing: Rights and enforcement," in New Frontiers in Dynamic Spectrum Access Networks. IEEE, April 2014.

[19] A. Agrawal and E. Ostrom, "Collective action, property rights, and decentralization in resource use in india and nepal," Politics \& Society, vol. 29, no. 4, pp. 485-514, 2001.

[20] B. Jessop, "The rise of governance and the risks of failure: the case of economic development," International Social Science Journal, vol. 50, no. 155 , pp. $29-45,1998$.

[21] O. E. Williamson, "The new institutional economics: Taking stock, looking ahead," Journal of Economic Literature, vol. 38, no. 3, pp. 595613, Sept 2000

[22] A. Agrawal, "Sustainable governance of common-pool resources: Context, methods, and politics," Annual Review of Anthropology, vol. 32, p. $24362,2003$.

[23] T. Hazlett, "The Wireless Craze, the Unlimited Bandwidth Myth, the Spectrum Auction Faux Pas, and the Punchline to Ronald Coase's 'Big Joke'," Harvard Journal of Law \& Technology, vol. 14, 2001.

[24] Y. Benkler, "Some economics of wireless communications," Harvard Journal of Law \& Technology, vol. 16, 2002. 
[25] W. Lehr, "The economic case for dedicated unlicensed spectrum below 3ghz," New America Foundation, Spectrum Series Working Paper 9, 2004.

[26] C. Caicedo and M. B. Weiss, "The viability of spectrum trading markets," IEEE Communications Magazine, vol. 43, no. 3, pp. 46-52, 2011.

[27] H. E. Smith, "Exclusion versus governance: Two strategies for delineating property rights," The Journal of Legal Studies, vol. 31, no. S2, pp. S453-S487, June 2002.

[28] L. A. Fennell, "Ostroms law: Property rights in the commons," International Journal of the Commons, vol. 5, no. 1, pp. 9 - 27, February 2011.

[29] N. Dolšak and E. Ostrom, "The challenges of the commons," in The Commons in the New Millenium: Challenges and Adaption, N. Dolšak and E. Ostrom, Eds. MIT Press, 2003.

[30] E. Schlager and E. Ostrom, "Property-rights regimes and natural resources: A conceptual analysis," Land Economics, vol. 68, no. 3, pp. 249-262, August 1992.

[31] N. Wormbs, "Technology-dependent commons: the example of frequency spectrum for broadcasting in Europe in the 1920s," International Journal of the Commons, vol. 5, no. 1, p. 92 109, February 2011.

[32] FCC, "In the matter of Marriott International, Inc," Federal Communications Commission, DA 14-1444.

[33] — - "Commission staff clarifies FCCs role regarding radio interference matters and its rules governing customer antennas and other unlicensed equipment," Federal Communications Commission, DA 04-1844.

[34] G. Majone, "The new european agencies: regulation by information," Journal of European Public Policy, vol. 4, no. 2, pp. 262-275, 1997.

[35] L. Doyle, J. Kibilda, T. Forde, and L. DaSilva, "Spectrum without bounds, networks without borders," Proceedings of the IEEE, vol. 103, no. 3, pp. 351-365, 2014.

[36] A. S. E. Consultancy, "Spectrum usage rights: Final report executive summary." [Online]. Available: http://www.itu.int/osg/spu/stn/spectrum/ spectrum_resources/spectrum_reform/Ofcom_SpectrumUageRights.pdf

[37] Ofcom, "Spectrum usage rights: Technology and usage neutral access to the radio spectrum." [Online]. Available: http://www.itu.int/osg/spu/stn/spectrum/spectrum_resources/ spectrum_reform/Ofcom_SpectrumUageRights.pdf

[38] M. Cave and P. Webb, "The unfinished history of usage rights for spectrum," Telecommunications Policy, vol. 36, pp. 293-300, 2012.

[39] E. Schlager and E. Ostrom, "Property-rights regimes and natural resources: A conceptual analysis," Land Economics, vol. 68, no. 3, pp. 249-262, August 1992.

[40] M. B. Weiss, W. H. Lehr, L. Cui, and M. Altamaimi, "Enforcement in dynamic spectrum access systems," in Telecommunications Policy Research Conference. Telecommunications Policy Research Conference, September 2012. [Online]. Available: http://d-scholarship.pitt.edu/13609/

[41] M. B. Weiss, S. Delaere, and W. H. Lehr, "Sensing as a service: An exploration into the practical implementation of DSA," in IEEE DySPAN, 2010.

[42] C. H. Sterling, P. Bernt, and M. B. Weiss, Shaping American Telecommunications: A History of Technology, Policy and Economics. Lawrence Erlbaum Associates, 2006.

[43] M. Altamimi, "Spectrum sharing: Quantifying the benefits of different enforcement scenarios," Ph.D. dissertation, University of Pittsburgh, 2014.

[44] FCC, "Amendment of the Commissions Rules with Regard to Commercial Operations in the $3550-3650 \mathrm{MHz}$ Band," GN Docket No. 12-354. [Online]. Available: https://www.fcc.gov/document/ citizens-broadband-radio-service-ro

[45] M. Palola, M. Matinmikko, J. Prokkola, M. Mustonen, M. Heikkila, T. Kippola, S. Yrjola, V. Hartikainen, L. Tudose, A. Kivinen, J. Paavola, K. Heiska, T. Hanninen, and J. Okkonen, "Description of finnish licensed shared access (lsa) field trial using td-lte in $2.3 \mathrm{ghz}$ band," in Dynamic Spectrum Access Networks (DYSPAN), 2014 IEEE International Symposium on, April 2014, pp. 374-375.

[46] P. Marshall, "A view of the Google $3.5 \mathrm{GHz}$ spectrum access system," International Symposium on Applied Radio Technologies. [Online]. Available: http://www.its.bldrdoc.gov/isart/isart-2015-agenda.aspx

[47] M. M. Sohul, M. Yao, T. Yang, and J. H. Reed, "Spectrum access system for the citizen broadband radio service," IEEE Communications Magazine, vol. 53, no. 7, pp. 22-28, 2015.
[48] R. A. Posner, "Theories of Economic Regulation," Bell Journal of Economics, vol. 5, no. 2, pp. 335-358, Autumn 1974.

[49] P. Bernt and M. B. H. Weiss, International telecommunications. Carmel, Ind., USA: SAMS Pub, 1993.

[50] T. P. Hughes, "Technological momentum," in Technology and the Future, A. H. Teich, Ed. Bedford, Boston, MA, 2000, pp. 26-35.

[51] L. Suchman, "Configuration," in Inventive methods: The happening of the social, C. Lury and N. Wakeford, Eds. Routledge, 2012, pp. 48-60.

[52] K. Woyach and A. Sahai, "Why the caged cognitive radio sings," in New Frontiers in Dynamic Spectrum Access Networks (DySPAN), 2011 IEEE Symposium on, 2011, pp. 431-442. 